\title{
INFLUÊNCIA DE DIFERENTES MÉTODOS DE SEMEADURA PARA QUALIDADE FISIOLÓGICA DE SEMENTES DE Coriandrum sativum L.
}

\author{
Elisiane Martins de Lima ${ }^{1}$; Milena Maria²; Cosmo Rufino de Lima33 Pablo Radamés \\ Cabral de França ${ }^{4}$; Tony Monteiro da Silva ${ }^{5}$
}

\section{Introdução}

O coentro (Coriandrum sativum L.) originário da região Leste do Mediterrâneo e oeste da Ásia é uma hortaliça amplamente consumida na cozinha brasileira, sendo utilizada especialmente como condimento, tendo grande importância sobre tudo para a horticultura no Brasil. É considerada atualmente a segunda hortaliça folhosa que mais agrega valor de mercado para o país, com grande número de importação e produção nacional de sementes. A produção nacional de sementes está ligada diretamente ao sistema convencional, mas isso vem mudando ao logo dos anos com as diversas transformações que o meio ambiente vem sofrendo, seja ela natural ou pela ação do homem como também da crise socioeconômica, tem-se buscado à adaptação as novas tecnologias que preservem os recursos naturais existentes no meio em que vivemos.

Dentro desse contexto vem se destacando a produção de hortaliças, que está sendo bem trabalhada pela agricultura orgânica, devido ao crescimento no setor agrícola ganhando força em diversos países, independente do desenvolvimento. Mesmo com o crescimento do sistema orgânico dentro da agricultura não há muitas informações referentes à produção de hortaliças neste tipo de sistema, principalmente quanto à origem da semente e seu vigor, justificando a relevância de estudos que abordem esses aspectos. Assim objetivou-se neste trabalho verificar a influência de diferentes métodos de semeadura nas sementes de coentro, provenientes dos sistemas de cultivo orgânico e convencional.

\footnotetext{
${ }^{1}$ Graduanda em Agronomia, Instituto Federal de Educação, Ciência e Tecnologia de Pernambuco Campus Vitória de Santo Antão, Elisiane.ane@gmail.com

2 Graduanda em Agronomia, Instituto Federal de Educação, Ciência e Tecnologia de Pernambuco Campus Vitória de Santo Antão,

${ }^{3}$ Doutor em Agronomia, Professor Substituto, Instituto Federal de Educação, Ciência e Tecnologia de Pernambuco - Campus Vitória de Santo Antão, cosmoagr@hotmail.com

${ }^{4}$ Doutor em Agronomia, Pesquisador na modalidade DCR - Nível C pela FACEPE/CNPq, Instituto Federal de Educação, Ciência e Tecnologia de Pernambuco - Campus Vitória de Santo Antão, pabloradames@hotmail.com

${ }^{5}$ Técnico agropecuário - tonemonteiro2014@gmail.com
} 


\section{Fundamentação teórica}

O coentro é uma hortaliça herbácea anual pertencente à família Apiaceae, nativa da região leste do mediterrâneo e oeste da Ásia. No Brasil, as folhas são amplamente utilizadas como tempero na culinária, especialmente na região nordeste (Melo et al., 2003).

Seu cultivo, é praticado por pequenos a grandes produtores, e se encontra em expansão no país. É uma espécie de grande interesse socioeconômica, sendo pouco contemplado com pesquisas, principalmente em relação de sementes (Torres et al., 2012). As folhasde coentropodem ser utilizadas como fonte de vitaminas, pois são ricas em vitaminas A, B1, B2 e C, sendo boa fonte de cálcio e ferro.

É uma hortaliça condimentar de ciclo anual, que pode atingir $30 \mathrm{~cm}$ a $1 \mathrm{~m}$ de altura, com flores organizadas em umbelas e frutos globosos secos e pequenos, onde o diaquênio do coentro é um fruto-semente que é constituído de dois aquênios, sendo geralmente comercializado inteiro.

\section{Materiais e métodos}

O presente trabalho foi realizado no laboratório de análise de sementes do Instituto Federal de Educação, Ciência e Tecnologia de Pernambuco (IFPE) - Campus Vitória de Santo Antão, onde foram utilizadas as sementes de coentro (orgânicaconvencional) da variedade de coentro verdão que é mais produzida na região. As sementes convencionais foram adquiridas no comércio local, e a orgânica fornecida pelo laboratório de sementes do instituto. O experimento foi conduzido com quatro repetições e oito tratamentos, utilizando-se 25 sementes em cada caixa de gerbox ${ }^{\circledR}$, totalizando 800 sementes. Os tratamentos consistiram na germinação da semente fechada, aberta manualmente, aberta no pano e aberta no pilão. As sementes foram semeadas sobre os 64 papeis mata-borrão colocadas em caixas de gerbox ${ }^{\circledR}$, e levados para incubadora B.O.D. (Biochemical Oxigen Demand) a uma temperatura de $25^{\circ} \mathrm{C}$.

De acordo com o manual de regras para análise de sementes (RAS) (Brasil, 2009), a contagem de germinação inicia-se ao sétimo dia e termina ao décimo quarto, contudo no presente trabalho as avaliações de germinação ocorreram do quinto ao décimo terceiro dia após a semeadura, de acordo com o início das germinações das plântulas. Os testes realizados foram: porcentagem de germinação (\%G), porcentagem 
de primeira contagem de germinação (\%PC), índice de velocidade de germinação (IVG), comprimento de plântulas (CP) e massa seca de plântulas (M.S.P.).

O delineamento experimental utilizado no experimento foi o inteiramente casualizado, em esquema fatorial de $8 \times 4 \times 2$ (oito tratamentos, quatro repetições e duas variedades de sementes de coentro (orgânica e convencional). Os dados obtidos em porcentagem foram submetidos a comparação entre as médias pelo teste de Scott-Knott.

\section{Resultados e discussão}

De acordo com a Tabela 1, verifica-se que não houve diferença significativa entre os tratamentos para a porcentagem de germinação; notadamente, quando as sementes convencionais de $C$. sativum foram avaliadas pela primeira contagem de germinação constatou-se que os tratamentos 2, 3 e 4 (aberta manualmente, aberta com pano e aberta com pilão respectivamente) apresentarem maior vigor, não diferindo estatisticamente das sementes orgânicas dos tratamentos 7 e 8 (aberta no pano e no pilão respectivamente). Resultados semelhantes foram obtidos em trabalho desenvolvido por SILVA et al. (2012). Quanto aos resultados obtidos no índice de velocidade de germinação, pode-se observar que o tratamento 7 (quando as sementes foram abertas no pano) e tratamento 8 (sementes abertas no pilão), apresentaram menor vigor quando comparada com os outros tratamentos.

Tabela 1: Valores médios obtidos nos testes de germinação, primeira contagem de germinação e índice de velocidade de germinação (IVG) de sementes $C$. sativum. $\mathrm{C}=$ sementes convencionais e $\mathrm{O}=$ sementes orgânicas.

\begin{tabular}{cccc}
\hline Tratamento & Germinação $(\%)$ & $\begin{array}{c}\text { Primeira Contagem de } \\
\text { Germinação }(\%)\end{array}$ & IVG \\
\hline T1= Semente fechada/C & $99 \mathrm{a}$ & $66 \mathrm{~b}$ & $4,482 \mathrm{a}$ \\
\hline T2= Aberta manualmente/C & $100 \mathrm{a}$ & $98 \mathrm{a}$ & $4,952 \mathrm{a}$ \\
\hline T3= Aberta com pano/C & $100 \mathrm{a}$ & $98 \mathrm{a}$ & $4,950 \mathrm{a}$ \\
\hline T4= Aberta com Pilão/C & $100 \mathrm{a}$ & $98 \mathrm{a}$ & $4,943 \mathrm{a}$ \\
\hline T5= Semente fechada/O & $98 \mathrm{a}$ & $63 \mathrm{~b}$ & $4,433 \mathrm{a}$ \\
\hline T6= Aberta Manualmente/O & $88 \mathrm{a}$ & $80 \mathrm{~b}$ & $4,224 \mathrm{a}$ \\
\hline T7= Aberta no pano/O & $100 \mathrm{a}$ & $86 \mathrm{a}$ & $3,312 \mathrm{~b}$ \\
\hline T8= Aberta no Pilão/O & $99 \mathrm{a}$ & $92 \mathrm{a}$ & $2,931 \mathrm{~b}$ \\
\hline Fator & $\mathrm{F}$ & $\mathrm{F}$ & $\mathrm{F}$ \\
\hline Germinação & $1,1429 \mathrm{~ns}$ & $4,7085 * *$ & $8,3826 * *$ \\
\hline CV $(\%)$ & 7,84 & 15,46 & 12,45
\end{tabular}

Médias seguidas pela mesma letra minúscula na coluna, não diferem entre si pelo teste de Scott Knott a 5\% de probabilidade. ${ }^{\mathrm{ns}}$ não significativo ( $\mathrm{p}>=0.05$ ); **significativo ao nível de $1 \%$ de probabilidade $(\mathrm{p}<0.01$ ); *significativo ao nível de $5 \%$ de probabilidade $(0.01=<p<0.05)$. 
Conforme a Tabela 2, semelhantemente ao teste de germinação, constatou-se que na avaliação do vigor pelo comprimento das plântulas não apresentaram diferenças significativas, ou seja, os diferentes métodos utilizados de semeadura não interfiram no resultado final de desenvolvimento das plântulas. Já quando o vigor foi avaliado pela massa seca de plântulas verificou-se diferença significativa entre as sementes orgânicas e convencionais, sendo o tratamento 1 (semeadura utilizando semente fechada) aquele que apresentou maior vigor.

Tabela 2: Valores médios obtidos nos testes de vigor de comprimento e massa seca de plântulas de C. sativum. $\mathrm{C}=$ sementes convencionais e $\mathrm{O}=$ sementes orgânicas.

\begin{tabular}{|c|c|c|}
\hline Tratamentos & Comprimento de plântulas $(\mathrm{cm})$ & $\begin{array}{c}\text { Massa seca de } \\
\text { plântulas (g) }\end{array}$ \\
\hline $\mathrm{T} 1=$ Semente fechada/C & 7,467 a & $0,138 \mathrm{a}$ \\
\hline $\mathrm{T} 2=$ Aberta Manualmente $/ \mathrm{C}$ & $8,842 \mathrm{a}$ & $0,113 \mathrm{~b}$ \\
\hline $\mathrm{T} 3=$ Aberta com pano $/ \mathrm{C}$ & $7,557 \mathrm{a}$ & $0,113 \mathrm{~b}$ \\
\hline T4= Aberta com Pilão/C & $8,592 \mathrm{a}$ & $0,123 \mathrm{~b}$ \\
\hline T5= Semente fechada/O & $8,572 \mathrm{a}$ & $0,124 \mathrm{~b}$ \\
\hline T6= Aberta Manualmente/O & $8,012 \mathrm{a}$ & $0,054 \mathrm{~d}$ \\
\hline $\mathrm{T} 7=$ Aberta no pano/O & $9,615 \mathrm{a}$ & $0,063 \mathrm{~d}$ \\
\hline T8= Aberta no Pilão/O & $9,574 \mathrm{a}$ & $0,080 \mathrm{c}$ \\
\hline Fator & $\mathrm{F}$ & $\mathrm{F}$ \\
\hline Primeira germinação & $1,1390 \mathrm{~ns}$ & $34,2011 * *$ \\
\hline $\mathrm{CV} \%$ & 15,74 & 10,43 \\
\hline
\end{tabular}

\section{Conclusões}

As sementes convencionais de Coriandrum sativum quando semeadas fechadas apresentam menor qualidade fisiológica;

As sementes convencionais de coentro aberta manualmente, com pano e com pilão, bem como às orgânicas aberta no pano e no pilão mostram maior vigor na avaliação do potencial fisiológico. 


\section{Referências}

BRASIL. Ministério da Agricultura, Pecuária e Abastecimento. Regras para análise de sementes. Ministério da Agricultura, Pecuária e Abastecimento. Secretaria de Defesa Agropecuária. Brasília: Mapa/ACS, 2009. 399p.

DANTAS, M.R.S.; TORRES, S.B. Vigor de sementes de rúcula e desempenho das plantas em campo. Revista Brasileira de Sementes, v.32, p.49-57, 2010.

KIKUTI, A.L.P.; MARCOS FILHO, J. Potencial fisiológico de sementes de couve-flor e desempenho das plantas em campo. Revista Brasileira de Sementes, v.29, p.107-13, 2007.

SILVA, M.A.D.; COELHO JÚNIOR, L.F.; SANTOS, A.P. "Vigor de sementes de coentro (Coriandrum sativum L.) provenientes de sistemas orgânico e convencional." Revista Brasileira de plantas medicinais, v.14, p.192-196, 2012. 